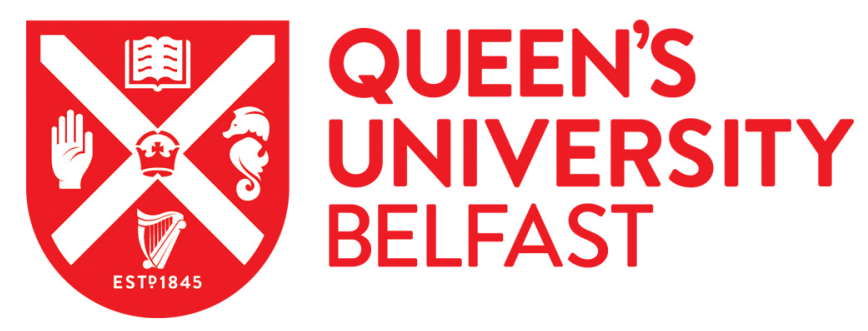

\title{
Fabrication and Ms Conduct: Scrutinising Practice Through Feminist Theory
}

Morrow, R., \& Belford, P. (2012). Fabrication and Ms Conduct: Scrutinising Practice Through Feminist Theory. Architectural Theory Review, 17(2-3), 399-415. https://doi.org/10.1080/13264826.2012.741607

\author{
Published in: \\ Architectural Theory Review
}

Document Version:

Peer reviewed version

Queen's University Belfast - Research Portal:

Link to publication record in Queen's University Belfast Research Portal

Publisher rights

This is an Author's Accepted Manuscript of an article published in Architectural Theory Review, Volume 17, Issue 2-3, 2012 [copyright Taylor \& Francis], available online at: 10.1080/13264826.2012.741607

\section{General rights}

Copyright for the publications made accessible via the Queen's University Belfast Research Portal is retained by the author(s) and / or other copyright owners and it is a condition of accessing these publications that users recognise and abide by the legal requirements associated with these rights.

Take down policy

The Research Portal is Queen's institutional repository that provides access to Queen's research output. Every effort has been made to ensure that content in the Research Portal does not infringe any person's rights, or applicable UK laws. If you discover content in the Research Portal that you believe breaches copyright or violates any law, please contact openaccess@qub.ac.uk. 
Fabrication and Ms. Conduct: scrutinising practice through feminist theory

\author{
Ruth Morrow and Patricia Belford \\ Queen's University Belfast ruth.morrow@qub.ac.uk \\ University of Ulster t.belford@ulster.ac.uk
}

\begin{abstract}
:
This paper describes a collaborative practice between an architect and textile designer: its outcomes, and the critical theoretical and feminist contexts from which the practice evolved and to which it still responds. The practice advocates the interweaving of more than the yarns, material and cultures on which it is physically based, but also the intertwining of feminist theory, practice and technology as a means to advance the discourse of architectural practice. This is a response to Sherry Ahrentzen's charge to feminist scholars and practitioners, to "embrace not only the abstract conceptual nature of much postmodernist theorizing, but also that derived from the serious "hanging out", looking at, listening to, scrutinising and theorizing lived experiences of the everyday": in this instance the everyday practice of combining concrete and textiles.
\end{abstract}

In the early phases of feminism its arguments, processes or products were understandably defined in opposition to the dominant culture. This led to the kind of contentious binary stereotypes discussed by Diana Agrest and her colleagues in their introduction to The Sex of Architecture, "that man builds and woman inhabits; that man is outside and woman is inside; that man is public and woman is private". Indeed I (the paper's first author) have examined and tested such relationships in my own teaching and writing about architectural education, building towards a feminist pedagogy of inclusion that makes use of oppositional relationships whilst conditioning them through phrases such as "not always" and "as well as". (see Table 1$)^{2}$

\begin{tabular}{|c|c|}
\hline Feminised Space & Feminised Practice \\
\hline Process as well as product & Collective, not always individualistic \\
User as well as use & Listening, not always telling \\
Experience as well as knowledge & Facilitating, not always controlling \\
Content as well as style & Non-hierarchical, not always hierarchical \\
Temporal as well as frozen & Fluid, not always fixed \\
Everyday as well as iconic & Doubtful, not always certain \\
Multi-sensorial as well as visual & \\
All-the-spaces-in-between as well as the & \\
public/private divide & \\
\hline
\end{tabular}

Table 1 
However, whilst feminist theorists raise genuine concerns that binary relationships might trap women into one form of practice, Tactility Factory (TF), whose work is discussed in this paper, has at its core just such an oppositional device: to make hard things soft. Working with a clear but provocative concept can be a struggle, not least because what we want to achieve is less dichotomous and more subtle than literally making hard things soft. The end goal may ultimately be unachievable and we may have to settle with "making hard things softer", nevertheless the interim results are proving to be radical and unique.

This paper will begin by outlining the nature of $\mathrm{TF}$, including an explanation of the materials and technologies it has developed and the resultant designs and applications. The main focus of the paper is, however, to site the practice theoretically, by drawing on both feminist and mainstream architectural theory. It will discuss some of the theoretical influences on the work and relationships to other precedents in architecture; and then examine TF's approach to practice and technology within the context of feminism. It will conclude with an outline of what has been learned, whether the work is feminist in process or outcome; and how it relates to the concerns raised in Fowler and Wilson's 'Women Architects and their Discontents,' the paper at the centre of this special issue.

\section{The Practice of Tactility Factory}

Tactility Factory is a collaborative part-time practice between two women, one a textile designer, the other an architect. It evolved initially within academia, but over the last two years has resided in the commercial world, funded by start-up grants and innovation awards and gradually picking up commissions, commercial interest and private investment. Both co-founders continue to straddle the sometimes incompatible worlds of academia and practice.

Tactility Factory develops, manufactures and commercialises patented technology that embeds textiles permanently onto the surface of concrete. We chose to concentrate on concrete since it is a ubiquitous, low-tech material but also one which has some negative characteristics. It is generally perceived as a harsh, unsustainable material with little emotional value though many technical and structural advantages. Whilst the architecture profession has sustained its passion for concrete, viewing it as an essential architectural material, that view is in sharp contrast to the rest of the populace, who regard concrete with scepticism. TF empathises with this "popular" critique and aims to confront the negative characteristics of concrete simply because it is a global material and impacts on the lives of many. TF applies textile techniques, technologies and most importantly "textile thinking" to address the social and sustainable limitations of concrete, expanding its potential by turning a cold, grey, acoustically harsh and unappealing substance into something warm, colourful, acoustically soft and appealing.

It has taken TF several years of research, always working part-time, to identify and refine the correct materials and technologies that can be used to combine textile and concrete manufacturing processes. The technologies developed allow the concrete and textiles to "co-form" the surface of the "skins". We manipulate the balance of the constituent parts in the concrete, but the real technical ingenuity of the concrete skins lies in the textiles. 
TF constructs its own textiles specifically and only for use in concrete, using carefully sourced base fabrics. Yarns must be able to survive both in the alkaline environment of concrete and the acidic environment of the textile processes. We have had to work hard to understand how differently structured and finished textiles react within the concrete. The aim is for the textiles to become fully blended with the concrete and for that some degree of shrinkage of the textiles is preferable. In the more extreme cases this helps to form very articulated concrete surfaces without the need of complex mould technology. It is the textiles, through their formulation and design that manipulate the concrete into chosen patterns and designs. No pattern is as random as it looks; all are controlled and predictable and can be as precise and as delineated as required.

Of the many techniques developed, three combinations have been commercialised to date: Linen Concrete, Velvet Concrete and Stitched Concrete. All use specifically designed, multi-layered textiles and techniques, and all require different concrete "recipes". The results are highly tactile, offering what we sometimes describe as an "oohouch" experience!

\section{(IMAGE 1: IMAGE 2: IMAGE 3:}

The surface designs come from a range of sources: architectural detail in historic fanlights, cornices and plasterwork; ironic visual reference to the "peace walls" of Belfast; ${ }^{3}$ historic and contemporary textile motifs; and reworkings of iconic designs such as one of Augustus Pugin's textile designs from 1850.

\section{(IMAGE 4- IMAGE 5 )}

The resultant skins (10mm thick) are robust yet can be manipulated in colour, pattern and form (flat, curved or folded). They can be applied to existing surfaces, much like wallpaper, or they can be integrated into precast concrete elements. TF skins are of interest to the cement and concrete industries which need to maintain their markets in ways that address the sustainability agenda. ${ }^{4}$ The most prevalent argument for concrete meeting sustainable agendas lies in its ability to increase the thermal mass of buildings and hence decrease the energy consumption related to heating and cooling. The result is an increase in the amount of exposed concrete: a condition many clients and users are concerned about By casting TF skins onto concrete, surfaces can be visually and acoustically enhanced without losing their effectiveness in thermal mass. So there are opportunities for TF skins to have wider application beyond the applied and decorative markets.

\section{Influences and Precedents}

From the beginning, TF has held a fundamental conceptual aim: to make hard things soft, in order to increase tactility in the built environment. This aim was informed by previous work in feminism, inclusive design and designing for disability, as they relate to the built environment. One such influence is the feminist author bell hooks, who has provided a guiding light for our practice. In her 1989 biographical-theoretical essay, "Choosing the Margin as a Space of Radical Openness" hooks documents her own struggles, as a black 
woman becoming an educated social activist and author. ${ }^{5}$ Most relevant to TF's practice are hooks' ideas on "the politics of location". She incites us to move with her to the location of radical operation; to choose not to locate oneself on the side of what she calls the "colonizing mentality", but to stand in political resistance. She writes that: "The choice is crucial. It shapes and determines our response to existing cultural practice and our capacity to envision new, alternative, oppositional aesthetic acts." ${ }^{6}$ At the same time, she also speaks of the need to use the oppressor's language in order to communicate. So even when one occupies the margins, one may still need to make use of mainstream tools in order to function.

This is a radical standpoint, and when translated to the work of TF, it allows us to acknowledge that we work within worlds that are not naturally ours (the worlds of business and concrete). These are not places where we feel wholly at ease, yet we understand the importance of holding that position; and of making use of, and responding to, those contexts and cultures.

We are also influenced by the nineteenth century short novel The Yellow Wallpaper by Charlotte Perkins Gilman, first published by the Feminist Press in 1892. It has acted as a muse for TF on several levels. It is the story of a woman suffering from post-natal depression, confined by her husband to an attic bedroom. In that sky-lit room, the yellow wallpaper becomes her obsession, her world and finally the manifestation of her madness. "I'm getting really fond of the room in spite of the wall-paper. Perhaps because of the wall-paper. It dwells in my mind so!"7 The woman is denied pens and paper for writing and as her mental health deteriorates, she narrates the wallpaper - charting how the patterns within patterns of the yellow wallpaper appear and disappear depending on light, time and mood. Ultimately, she becomes part of the wallpaper, taken into the skin of the wall and freed from her torment. Whilst on one level it is a distressing story, there is also a form of liberation in it; a discovery of the complexity and potential of simple patterns within patterns; an intellectual release in allowing the creative mind to find an other place to exist, a place of "delirious" freedom.

The Yellow Wallpaper allows TF to understand itself as that well-lit attic room; as a place to be free of the orthodoxy of conventional practice and to escape through pattern and surface to a place of other potentials. TF is the place in which the woman in The Yellow Wallpaper can also regain her sanity. One of TF's aims is "to make mad ideas sane", but in order to do that, we must create a space to allow for madness in the first place, from whence sanity can be retrieved. Perhaps this helps to complete the cycle of the woman in the attic room.

The enduring, sometimes uneasy, but ever-evolving historic relationship between architecture and textiles is another site of interest for TF. ${ }^{8}$ Beginning with Gottfried Semper's (1803-1879) theories on the interconnection between textiles and the origins of architecture, along with his development of a "Principle of Dressing" in relation to architecture, the line of influence continues through the work of architects such as Josef Hoffman and Henry Van de Velde, who simultaneously designed architecture and clothing at the end of the nineteenth and beginning of the twentieth century. This was 
followed by modernism's rejection of all things decorative, influenced by Adolf Loos' 1913 essay "Ornament and Crime," . The lineage can be traced onward to those architects whose work has engaged creatively with surface, for example Paul Rudolf's seminal surface treatments in the Art and Architecture Building at Yale University, ${ }^{10}$ and the work of the Spanish architect Miguel Fisac in 1970s and 1980s. ${ }^{11}$ More recently developments in nano and smart textiles also informs the work of TF. ${ }^{12}$

Through the process of historic contextualization and analysis, we have found examples of architecture where textiles are used either literally or conceptually. When used literally, it would seem that architects are uncomfortable with textiles' ability to hang, furl and drape; perhaps because they might impinge on pure architectural spaces, perhaps because in that state they represent something to "be managed". The predominant use of textiles in the built environment is where they are held within framed and strictly regulated structures; taut, stretched and controlled; they are the "smart" petrochemical constituents of space-age lightweight structures, seen but not touched. Where textiles are used conceptually, it is their characteristics of "lightness, surface, complexity and movement" that mirror "architecture's shifts towards a more fluid state". ${ }^{13}$ Overall, the result is architecture that may look like and indeed may even appropriate textile technologies, but rarely feels like textiles. ${ }^{14}$

The contemporary efforts of Petra Blaisse and her practice Inside Outside ${ }^{15}$ has also informed the practice of TF. Her work ranges from landscapes to curtains. We admire the additional layering and richness that her textile work brings to architectural space. She engages with the weight of textiles, thinking how best to support the layers she creates. She considers the appearance and disappearance of the cloth; the space required to store large amounts of fabric, its acoustic profile, and its ability to wrap and create intimate sub-spaces. The light touch and adaptability Blaisse applies to textiles also relate to her work with natural planting, though here she talks of the difference between the growth of plants and the decay of cloth. ${ }^{16}$ It is useful to compare and contrast Blaisse's work to TF, especially since there is such an overlap in sensibility and materials. Like her we are interested in the contradictions between buildings and textiles. But whilst she understands textiles as impermanent or transitory, retracting to positions out of sight, we consider textile thinking and technology as a way to permanently "take place" and influence the technology and fabrication of hard things and, hopefully, of "hardened thought".

\section{Contextualising Tactility Factory's practice in feminist theory}

Sherry Ahrentzen's feminist analysis of architectural education and practice has opened up alternative ways to think and act within architecture; gaps for other types of practice to exist. ${ }^{17}$ In her 2003 survey of architectural feminist theory and practice, "The Space Between the Studs", published in the feminist academic journal Signs, she seeks to "look for the invisible among the visible" and thus to identify what is missing (and why) in feminist theory and architectural practice. Expanding on Elizabeth Grosz's categories of "occupying" and "producing" as ways to consider architectural practice, Ahrentzen argues that "producing" is centred on the production of a building or "architecture-as- 
object". She explains that women as clients or consumers of architecture are best able to affect changes in spatial configurations by demanding new forms of programming. As architects, however, she asserts that there is increasingly less chance of affecting spatial reconfigurations, arguing that architects have traded their "control over the building program for control over formal imagery in the profession's pursuit to define itself primarily as a practice of representation". ${ }^{1}$

In terms of "occupying", Ahrentzen calls for a socially responsible architecture, one which is as much a social enterprise as an intellectual or technological product. She describes a feminist praxis of architecture which can "strive towards new ways of inhabiting", where architecture can be as much about people's relationship in, through and to space, as it is a relationship to the object of architecture.

Despite our admiration for Ahrentzen's thinking, TF's work sits uneasily across both categories. It is clearly involved in production, though in a way that stretches architectural practice beyond the production of buildings to include other built environment elements and materials. TF responds to a concern that the majority of those products, materials and components are designed to meet only technical specifications. We therefore seek to reinstate a "human" specification to the development of building products, considering this equal in importance to technical performance. Indeed the profoundest production challenges faced by TF do not lie with meeting technical specifications (since much of that work has been resolved by technologists before us), but rather with applying technological understanding in a way that produces artefacts and surfaces that people wish to interact with.

By renaming the surfaces as "skins," we gradually began to think of the TF outcomes within the concept of "craft" since they look and feel "crafted" and substantially "material" - not because they are worked by hand, but because they are considered through detail. In this way our approach echoes the ethos of the late Irish engineer Peter Rice: his concept of a "trace de la main and his injunction to "make real the presence of the material in use in the building, so that people warm to them, want to touch them, feel a sense of the material itself and of the people who made and designed it". ${ }^{19}$

We are reminded by Deborah Johnson that "domains of knowledge and skill mastered by men are called technical or technological while those mastered by women are considered crafts" ${ }^{20}$ TF asserts that the sense of craft is attained through the development and manipulation of new technologies mindful towards touch, thus contributing to current discourses around the reconceptualisation of "craft".

In the course of our work, we have concluded that when the designer is remote and nonconversant with the fabrication process, controlling the "experienced" quality of any resultant product can be immensely challenging. Without a connection to fabrication, the designer is restricted to the manipulation of conceptual and formal expressions and fails to directly inform the user's primary experience. This compounds Ahrentzen's fear that architectural practice becomes solely confined to the production of representations; a condition that TF challenges through its integrated approach to design and fabrication. 
Tactility Factory is not only focused on manufacturing products that address social and human concerns, but also on the manner in which it practises. This is most clearly witnessed in its forms of collaboration and communication. In its early stages, TF was driven by a singular collaboration between a textile designer and an architect. Whilst this remains at its core, the practice has progressed to include collaborations with precast concrete specialists, mould makers, digital textile designers, weavers, embroiderers, graphic designers, marketing consultants, business advisors and patent attorneys. Many of the people who contribute to the project come neither from identifiable "creative" professions nor modes of practice that have much in common. But they all contribute through their expertise and efforts to the application of creative ideas and to the resolution of operational problems. Given the cultural and professional diversity of those involved in TF, we have come to understand the importance of recognising and giving credence to personal motivations. Some collaborators are motivated by the wish to experiment with familiar technologies; others by holding true to a long established work process. Doing so helps to build a common culture and agreed direction for the company. The intensity of learning around collaboration has been due in no small part to the hybrid nature of the project. Bringing concrete and textile cultures together in one project is a continuous challenge.

Given that this is a multi-layered project, the scope for experimentation across the material technology of concrete moulds, concrete mixes and multiple textile techniques means that the potential for diversion, confusion and error is multiplied many times over. Communication and documentation is therefore crucial. This need is heightened by the fact that we are all part-time in TF. Being "part-time" is a state familiar to many women in the workplace and is one of the issues identified by Fowler and Wilson that affects women's progression in the architecture profession. ${ }^{21}$ In TF we counteract the impact of being part-time by using cloud technology to post online diaries, schedules of work, budgets, tables of trials etc. However, we meet collectively to critique and evolve the work. Over time we have also renamed processes and products in a third language, not discipline-centred but rather specific to TF. The development of this "third" nomenclature seems a necessary outcome of hybrid collaborative practices that stretch across diverse cultures.

Tactility Factory communicates beyond its own boundaries. From the beginning it has used a blog (girliconcrete) ${ }^{22}$, as well as teaching and workshops to exchange outcomes and reflections. We are enthusiastic about the work and want to share but, rather than present polished anonymous outcomes, we disclose the blind alleys, failed trials and raw results as a means to support others in similar territories. This interaction means that we are able to draw on and exchange advice beyond our geographical and disciplinary confines.

\section{Tactility, Technology and Feminism}

The central objective of TF is to enhance people's experience of the built environment by increasing levels of tactility through the manipulation of technology. In this section, the paper will now turn to examining TF's relationship to tactility and technology, in the 
context of feminist theory. Over the course of the project, the working methods and skills of the textile designer have challenged and enlightened the architect's processes, causing the architect to reflect on certain aspects in respect to contemporary architecture practice. In particular the textile designer's skill in creating rich tactile surfaces through the application of appropriate technologies has caused the architect to reflect on the degree of this skill within architecture.

Tactility is certainly referenced in both feminist and mainstream architectural critiques that challenge the dominance of the visual and call for the corporeal and psychological experience of space to be better understood and elevated in significance. ${ }^{23}$

Phenomenologists, notably those who influence and practise architecture ${ }^{24}$ position tactility and a sense of touch within their wider concern for the experiential in architecture, and its material manifestations. Juhani Pallasmaa, whose interest in the relationship between the senses and architecture is well documented across several publications, argues in his most recent work that:

The boundary line between the self and the world is identified by our senses. Our contact with the world takes place through the skin of the self by means of specialized art of our enveloping membrane. All the sense, including vision, are extensions of the tactile sense; the senses are specialisations of skin tissue, and all sensory experiences are modes of touching and thus related to tactility. ${ }^{25}$

Pallasmaa understands the centrality of touch within the body's sense of itself and the world around it, but also argues that most contemporary architecture falls short of delivering a full response: "Our architecture may entice and amuse the eye, but it does not provide a domicile for the touch of our bodies, memories and dreams" ${ }^{\prime 26}$. In contrast, interacting with a piece of fabric is personal and unique; a cosy, cuddly, slippy, scratchy, warm encounter. Simultaneously, one experiences an intimate physical and aesthetic reaction. Behind this emotive experience of textiles lies the same depth of technical expertise as is required in the making of space. It is therefore the remarkable achievement of textile designers to take "hard-core" chemical and mechanical processes (abrasive and corrosive technologies) and use them to transform and combine yarns into an artefact that evokes strong physical responses. Technology may be central to textile designers' processes, but it is rarely present in the final experience of their product ${ }^{27}$. In this respect, the textile designers' skill in using technology gives architects much to think about.

Perhaps this instantiates Judy Wajcman's general observation on the 'masculine culture of technology'; ${ }^{28}$ she argues that technology is conceived in terms of industrial processes (more closely associated with men and their roles in society) rather than domestic ones. Women's involvement with technology is therefore marginalised and where they have contributed to larger scale processes, this involvement has often gone un-credited or undocumented. Autumn Stanley's work has uncovered some of the undervalued contributions women have made to the development of patented technologies. ${ }^{29}$ She identifies women now credited with advancing the technology of weaving looms, sewing machines, washing machines, and typewriters (it's interesting to note the association with textiles), although it was the names of their husbands or legal advisors that appeared on 
the patents. Whilst the terminology and culture of technology may remain outside many womens' interests, this does not mean they are not already engaged in revising, developing and challenging the technologies that surround them. Certainly within TF it is the textiles that are the most advanced component of the overall technology package. It is through the development and manipulation of the textiles that the concrete is controlled and the overall performance enhanced.

Feminist theorists have done much in recent years to address women's lack of involvement in technology by taking a closer look at what is meant by technology, and teasing out its relationship to and role in society. In Feminism Confronts Technology, Wacjman provides an expanded definition of technology which draws out three layers of meaning. Firstly there are what Wajcman calls the "things" - the tools, artefacts, components, or pieces of software that traditionally encapsulate "technology". Secondly, technology is a form of knowledge about how to use, repair, make, and maintain artifacts. In Wajcman's understanding, technological things are useless without "know-how", a form of knowledge that she believes is "visual, even tactile, rather than simply verbal or mathematical". Thirdly, technology is about what people do as well as know. For Wajcman, human activity and interaction are implicit components of technology. Through the arena of science and technology studies this view has become more established and the focus has broadened to encompass not only artefacts but also the socio-technical systems which surround them. As Johnson explains, 'Technology is the combination of artifacts together with social practices, social relationships and arrangements, social institutions, and systems of knowledge. ${ }^{, 31}$

\section{Conclusion}

This essay has been driven by Ahrentzen's charge: not only to embrace abstract and conceptual theories, but also to "hang-out", scrutinise and theorise the lived experience of the everyday. The "everyday" of this paper is a collaboration that has grown between an architect and textile designer and sustained itself over six years, resulting in its own specific technologies, approaches, language and approach to practice. In this process, some specific reflections for feminist theory have arisen.

Many of the influences and precedents that underpin TF's work have been acknowledged here. The work of others provides much inspiration, reflection and support for the practice. The texts of bell hooks occupy a clear and poignant place in the conscience of TF. She prompts us to generate "a counter-hegemonic discourse that is not just found in words but in the habits of being and the way one lives"; 32 or as TF would see it, the way one practises. The world of business and manufacturing is still, to some extent, foreign territory and we recognise that it a natural default to follow in the footsteps of others. But when so few of those footsteps have belonged to women, it is easy to adopt patterns of behaviour, language and attitudes that are not naturally ours, and thus fit uncomfortably. We are more mindful of those instances and of our responsibility to act critically because of the work of hooks and others like her.

From Gilman's Yellow Wallpaper we derive the confidence to create a space where messing around and obsession are legitimised. Through the work of such people as hooks 
and Gilman we understand the strength, potential and need for critical and unorthodox approaches. And while it may be perceived as risky to admit it, there is also a commercial dimension to crafting a distinctive place and (feminist) approach for TF. We are reminded of Fowler and Wilson's observations that many of those who changed the direction of architecture and "broke the rules" did so through "their knowledge of the historical field and love of the architectural game" ${ }^{33}$ For TF our field of influence is wider than the traditional view of architecture and whilst we still love and value much of the discipline, we are critical of the "architectural game".

Whilst feminist praxis naturally calls for collaboration, and much has been written about the strength of working collaboratively across cultures or professional disciplines, much more needs to be said about the practicalities of bringing together technical and cultural backgrounds that appear antithetical to one another (as concrete does to textiles). Collaboration is essential for TF simply because the practice spans a breadth of knowledge and expertise that requires a chain of collaborators. In TF that chain is formed into a non-hierarchical circle. In hybrid territories collaboration begins and ends with an understanding of the interests and motivations of the individuals involved. Such challenging collaborations offer the potential to crack open normative conventions within a range of professions. More specifically, they may release new forms of architectural practice.

For TF, one of those new outcomes has been the technological process - more particularly, how that process has allowed us to put human interaction right at the heart of the work, manufacturing "skins" that provide people with aesthetic and sensual interactions. TF is able to interweave the fabrication and design processes to the point where they exist in parallel, informed and formed by one another. We believe that collapsing the space between representation and fabrication results in surfaces that speak as textiles do, in an intimate and personal way. No matter how technically complex or theoretically informed the designs are, or how efficient or innovative the manufacturing processes become, the single most important characteristic of TF skins is the quality of the user experience they offer.

Does this mean that TF generates feminist technology? Layne in the introduction to Feminism and Technology asks: "Are feminist technologies simply or necessarily artifacts 'designed by women, for women'? If a technology is feminist, how did it get that way? Is the feminism in the design process, in the thing itself, in the way it is marketed, or in the way it is used by women and/or by men?"34 In the case of TF, whilst the process was initiated and led by two women, an array of people of both genders has contributed to its development; and while the process is certainly informed by feminism, we would agree with Layne's concluding statement that "what matters is their [technologies'] effect and not their intended effect". In other words, only the user can be the real judge of that question.

One thing we can be sure of is Wajcman's call for more women to be involved in the technical processes that shape our world. She quotes Mike Cooley, a radical trade union leader in the late 1970s and author of the poignantly titled book, Architect or Bee? The 
human/technology relationship, who thought that more women should get involved in science and technology "to challenge and counteract the built-in male values; that we cease placing the objective above the subjective, the rational above the tacit, and the digital above analogical representation" ${ }^{35}$ Whilst women's access to formal technologies has been limited in the past by lack of power and resources, along with more insidious gender-based barriers, women have always sought to improve their lives and the lives of others by altering the technologies at hand. In TF, we are mindful that previous generations of women went un-credited within the patent process, and therefore we hold those particular outcomes of TF's work in much respect. ${ }^{36}$

In the first year of TF, we felt a need to express the concept of the work as clearly as possible. Our samples were raw, the concepts clumsy and the technology far from resolved, but we wanted to allow others to sense the scale of our ambition and share in the vision. We produced a short animation of a young woman walking through a concrete environment, gently tracing her hand over the surfaces, drawing out ornamental patterns from below the surface that released seed-heads into the air. Those images still represent our vision (mad as it may be!): to change the world, share unorthodox approaches, and make hard things softer.

IMAGE 6.

${ }^{1}$ Diana Agrest, Patricia Conway and Leslie Kanes-Weisman, The Sex of Architecture, New York: Harry N Abrams, 1996, 11.

${ }^{2}$ Table taken from: Ruth Morrow. 'Building Clouds, Drifting Walls' in Doina Petrescu (ed), Altering Practices, Feminist Politics and Poetics of Space. Routledge, 2007

${ }^{3}$ A 'Peace wall' is a constructed barrier, typically walls topped off by further fencing, used to separate nationalist and loyalist communities in Belfast, Northern Ireland. The current number of walls, just under 100, has increased since the 1998 Peace Process.

${ }^{4}$ Tactility Factory was commissioned by one of the world's largest cement manufacturers to provide the centre piece element for their "cool concrete" pavilion at Ecobuild, UK 2012.

5 bell hooks, "Choosing the Margins as a Space of Radical Openness", in Rendell, Penner and Borden, Gender Space Architecture, An interdisciplinary introduction, London: Routledge, 2000, 203-221

${ }^{6}$ hooks, "Choosing the Margins as a Space of Radical Openness", 203

${ }^{7}$ Charlotte Perkins Gilman, The Yellow Wallpaper, revised edition, New York: The Feminist Press at CUNY, 1996.

${ }^{8}$ Leila W. Kinney, "Fashion and Fabrication in Modern Architecture", Journal of the Society of Architectural Historians, 58, no. 3 (1999/2000): 472-81.

${ }^{9}$ William Tozer in his PhD thesis, 2011: "A Theory of Making: Architecture and Art in the practice of Adolf Loos", Bartlett School of Architecture, UCL, London, argues that this has been a false reading of Loos and that instead he used ornament and decoration as a means to denote the functional elements of architecture.

${ }^{10}$ Timothy M. Rohan, "Rendering the Surface: Paul Rudolph's Art and Architecture Building at Yale”, Grey Room, No. 1, The MIT Press, 2000, 84-107 
${ }^{11}$ See Miguel Fisac Foundation website, www.fundacionfisac.org

${ }^{12}$ Tactility Factory collaborated with Helen Storey (fashion designer) and Tony Ryan (nano chemist) on "Herself", 2010 - a concrete-coated dress used to illustrate how impregnated textiles can remove environmental pollutants; http://www.catalyticclothing.org/

${ }^{13}$ Mark Garcia (ed), "Architecture + Textiles = Architextiles" Special Edition of Architectural Design, Vol 76, No 6, London: Wiley-Academy, 2006.

${ }^{14}$ Ruth Morrow and Trish Belford, "Soft Garniture: Developing Hybrid Materials Between Academia and Industry", in S Roaf and A Bairstow (eds), The Oxford Conference: A Re-evaluation of Education in Architecture, Boston: WIT Press, 2008, 357-61.

${ }^{15}$ Practice website: www.insideoutside.nl

${ }^{16}$ Petra Blaisse, Inside Outside. Basel: Birkhauser, 2007

${ }^{17}$ Sherry Ahrentzen has authored and co-authored a range of publications in this area, including "The Space Between the Studs: Feminism and Architecture", Signs: Journal of Women in Culture and Society, 29, no. 1 (2003) 179-206; Linda Groat and Sherry Ahrentzen, "Voices for Change in Architectural Education: Seven Facets of Transformation from the Perspectives of Faculty Women", Journal of Architectural Education, 50, no. 4 (1997): 271-85; and Sherry Ahrentzen, "The F-Word in Architecture: Feminist Analyses in/of/for Architecture", in Thomas A. Dutton and Lian Hurst Mann (eds), Reconstructing Architecture: Critical Discourses and Social Practices, Minneapolis: University of Minnesota, 1996

${ }^{18}$ Ahrentzen, "The Space Between the Studs".

${ }^{19}$ Peter Rice, An Engineer Imagines, London: Ellipsis. 1994, 76

${ }^{20}$ Deborah G. Johnson, "Sorting out the Question of Feminist Technology", in Linda Layne, Sharra Vostral, and Kate Boyer, Feminist Technology. Chicago: University of Chicago Press, 2010, 37.

${ }^{21}$ Bridget Fowler and Fiona Wilson, "Women Architects and Their Discontents", Sociology 38 (2004): 101-18.

${ }^{22}$ Now part of the website http://tactilityfactory.com

${ }^{23}$ For feminist architectural critique, see Karen Franck and Bianca Lepori, Architecture from the Inside Out: From the Body, the Senses, the Site and the Community, Hoboken NJ: John Wiley \& Sons, 2007; see also David Michael Levin (ed.), Modernity and the Hegemony of Vision, Berkeley: University of California Press, 1993, and Juhani Pallasmaa, The Eyes of the Skin: Architecture and the Senses. London: Academy Group. 1996, both of which are representative of this strand of mainstream discussion. A recent addition, one which in its sleeve notes claims to track a generational shift towards new practices "engaged in the tactile world of matter" is Gail Peter Borden and Michael Meredith, Matter: Material Processes in Architectural Production, London: Routledge, 2012

${ }^{24}$ Maurice Merleau-Ponty, Christian Norberg-Schulz, Steen Eiler Rasmussen, Juhani Pallasmaa, Steven Holl, Peter Zumthor.

${ }^{25}$ Juhani Pallasmaa. The Thinking Hand, Existential and Embodied Wisdom in Architecture, AD Primer, Wiley, 2009, 100

${ }^{26}$ Pallasmaa. The Thinking Hand, Existential and Embodied Wisdom in Architecture, 102 
${ }^{27}$ Before meeting her architect co-founder, TF's textile designer never used the word 'technology' in the context of her work, despite the fact that she had run her own textile manufacturing company for many years.

${ }^{28}$ Judy Wajcman, Feminism Confronts Technology, Cambridge: Polity, 1991 (see ch. 6).

${ }^{29}$ Autumn Stanley, Mothers and Daughters of Invention: Notes for a Revised History of Technology, New Brunswick NJ: Rutgers University Press, 1995

${ }^{31}$ Johnson, "Sorting out the Question of Feminist Technology", 39

${ }^{32}$ bell hooks, "Choosing the Margins as a Space of Radical Openness", 206.

${ }^{33}$ Fowler and Wilson, "Women Architects and Their Discontents", 104.

${ }^{34}$ Linda Layne, Sharra Vostral, and Kate Boyer (eds), Feminist Technology, Chicago: University of Chicago Press, 2010, 7.

${ }^{35}$ Judy Wajcman, "Feminist Theories of Technology", Cambridge Journal of Economics, 34 (2010): 145.

${ }^{36}$ Both collaborators are listed as the inventors on three TF patents. 